\title{
Reproductive Ability of Hybrids of Striga aspera and Striga hermonthica
}

\author{
Emmanuel I. Aigbokhan, Dana K. Berner, and Lytton J. Musselman
}

First and second authors: International Institute of Tropical Agriculture, P.M.B. 5320, Ibadan, Nigeria; and third author: Department of Biological Sciences, Old Dominion University, Norfolk, VA 23529-0266.

Accepted for publication 2 March 1998.

\begin{abstract}
Aigbokhan, E. I., Berner, D. K., and Musselman, L. J. 1998. Reproductive ability of hybrids of Striga aspera and Striga hermonthica. Phytopathology 88:563-567.

Striga aspera and $S$. hermonthica are sympatric in Africa. Each may serve as virulent gene reservoirs for the other if they hybridize and their hybrids are virulent and fertile. Intraspecific and interspecific crosses were made within and between the species, and reproductive success was determined. Freshly harvested seeds from the parental and $\mathrm{F}_{1}$ crosses were tested over time for germination. Chromosome counts from shoottip squashes of seedlings of $S$. aspera were determined as $n=18$, and as

backcrossed to either parent. Reproductive success in all crosses ranged from 68 to $95 \%$ and seeds of all the crosses were viable, germinated on exposure to a synthetic germination stimulant, and were pathogenic on maize. Seeds from the hybrids and backcrosses were less viable and germinable than either parent, suggesting that the two species were not $100 \%$ compatible. Results suggest that the two species are closely related, but are separate taxa, perhaps at the subspecies level. Seed dormancy for both species and the $F_{1}$ hybrids was less than 84 days after pollination. Germination of S. hermonthica seeds reached $31 \%$ at 28 days after pollination. Frequently occurring seed germination peaks were observed for all the seeds tested.
\end{abstract} $n=19$ for $S$. hermonthica. Hybridization results indicated that $S$. aspera and $S$. hermonthica could be intercrossed and their hybrids successfully

Striga hermonthica (Del.) Benth. and S. aspera (Willd.) Benth. (Scrophulariaceae) are common parasitic plants found in West Africa. Many reports exist on the devastating effects of S. hermonthica on cereals like maize (Zea mays L.), sorghum (Sorghum bicolor (L.) Moench), rice (Oryza sativa L.), and millet (Pennisetum glaucum (L.) R. Br.) in this region $(6,11,12)$. S. aspera, which is commonly found growing on wild grasses, has also been reported as a local pest of 'fonio' (Digitaria exilis (Kippist) Stapf.), rice, and maize in the savannas of Africa $(11,14)$. Both parasites are similar in growth habit and flower color, but can be distinguished by some taxonomic features (13). The position of the bend of the corolla tube of $S$. hermonthica is located just above the calyx, and the corolla tube lacks glandular hairs. With $S$. aspera, the corolla tube extends well above the calyx before bending, and glandular hairs are apparent on the corolla tube. The ratio of the corolla tube length below and above the bend was determined as 1.5:1 for S. aspera and 0.9:1 for $S$. hermonthica (10). These are reported to be the only two obligate allogamous species found in the genus, and individual plants are self-incompatible (15). Musselman et al. (7) reported that both species shared common insect pollinators, could be intercrossed, and successfully set seeds. They did not determine if these hybrid seeds were germinable or pathogenic on any host. There are conflicting reports on the meiotic chromosome counts for the two species. Musselman et al. (7) reported that the chromosome number for $S$. aspera was $n=27$, and for $S$. hermonthica was $n=$ 32. In another report (4), the chromosome number for $S$. aspera was $n=30$, and for $S$. hermonthica was $n=40$. Parker and Riches (11) suggested that because of the reportedly large differences in chromosome numbers between the species, the likelihood of producing viable hybrid seeds was remote. There are neither hybridization reports with $F_{1}$ plants from these interspecific crosses nor seed germination reports on $\mathrm{F}_{2}$ and backcross progeny from $\mathrm{F}_{1}$ crosses.

Corresponding author: D. K. Berner; E-mail address: d.berner@cgnet.com

Publication no. P-1998-0421-01R

(C) 1998 The American Phytopathological Society
Additional keywords: chromosome number, Striga hybrids, viability, virulence.
The purposes of this study were to (i) determine the degree of reproductive success within and between crosses of $S$. hermonthica and S. aspera; (ii) determine the chromosome numbers of $S$. hermonthica and $S$. aspera; (iii) determine if the $\mathrm{F}_{1}, \mathrm{~F}_{2}$, and backcrossed seeds of the two species were viable, germinable, and pathogenic on maize; and (iv) determine length of dormancy and germination capacity over time of freshly harvested seeds of $S$. aspera, $S$. hermonthica, and their $\mathrm{F}_{1}$ hybrids.

\section{MATERIALS AND METHODS}

Viability tests. The tetrazolium chloride red test (1) was used to determine seed viability in conditioned parasite seeds; parasite seeds require conditioning under appropriate moisture and temperature conditions for specific periods before they respond to any germination stimuli (16). Conditioning was done by surface-disinfesting the seeds in a solution of $1 \%$ sodium hypochlorite for $5 \mathrm{~min}$. About 30 to 60 seeds were then placed on 2-mm-diameter Whatman GF/C glass-fiber filter-paper disks (Whatman International, Ltd., Maidstone, England). Four of these disks were placed on moist Whatman No. 1 filter paper (Whatman International, Ltd.) in a petri dish. The petri dishes containing the seeds were incubated in complete darkness at $25^{\circ} \mathrm{C}$ for 14 days. The filter paper in the petri dishes was moistened daily with sterile deionized water. Seed viability was determined by exposing the conditioned seeds to a $1 \%$ aqueous solution of 2,3,5-triphenyl-tetrazolium chloride (TTR) solution ( $\mathrm{pH} 7)$. To each disk, three to four drops of TTR were applied so that all exposed portions of the seed were in contact with the solution. Treated seeds were incubated in total darkness at $35^{\circ} \mathrm{C}$ for $48 \mathrm{~h}$ and afterwards observed for red-stained endosperm under a dissecting microscope. Seeds with red-stained endosperm were regarded as viable, while those with colorless endosperm were considered nonviable. To ease the detection of the red stain in seeds with highly pigmented seed coats, a few drops of commercial bleach solution were applied to decolorize the seed coats before observation. The ratio of seeds with red-stained endosperm to the total number of seeds on each disk was used to estimate percent seed viability. 
Germination tests. Germination tests on all parasite seeds were conducted using an aqueous solution of GR24 (5) as a germination stimulant. Seeds used for the germination test were conditioned as previously described. After the conditioning process, the filterpaper disks with the Striga seeds were blotted on sterile paper to remove excess moisture and transferred directly onto another petri dish. Two drops $(50 \mu \mathrm{l})$ of $10 \mathrm{mg}$ of GR24 solution per liter were applied to each disk. The petri dishes were then placed in a dark incubator at $30^{\circ} \mathrm{C}$ for $48 \mathrm{~h}$. Germinated seeds with emerging radicles were observed under a dissecting microscope. Percent germination was calculated from the ratio of seeds with emerging radicles to the total number of seeds on each disk.

Hybridization. Artificial hand-pollination was carried out under complete insect exclusion in a screenhouse at the International Institute of Tropical Agriculture, Ibadan, Nigeria, between November 1994 and May 1996. S. hermonthica (SH) and S. aspera (SA) plants used in the crosses were obtained from seeds collected from Mokwa, Nigeria, in 1993 and grown by infesting unsterilized soil in pots with $0.05 \mathrm{~g}$ (about 3,000) of germinable seeds. Soil in individual pots was infested with either of the species, but not both. Four days after infestation, a SH-susceptible maize hybrid, cultivar 8338-1, was planted. Maize planting was staggered at weekly intervals to synchronize flowering time between the species. This was done by planting maize in the later-maturing $\mathrm{SH}-$ infested pots first and in the earlier-maturing SA-infested pots 4 weeks later. This was done for 5 consecutive weeks, planting 15 pots containing each species each week. A total of 75 pots of each species were planted. Emasculation of the flowers was done by gently pulling out the corolla tube, leaving the calyx tube enclosing the gynoecium (stigma, style, and ovary). Pollen was obtained from the male parent by longitudinally cutting open the corolla tube and collecting with an inoculating needle the mass of whitish pollen grains deposited on the walls of the corolla. Pollen was immediately transferred to the stigma of the female parent. Reciprocal crosses within and between the two species were made on randomly selected plants. Capsules containing seeds were harvested 14 days after pollination (DAP) and were allowed to dry in the screenhouse under ambient conditions until the capsules dehisced, releasing the seeds. Reproductive success was measured as the percentage of pollinated flowers that produced capsules containing seeds. To determine whether the $F_{1}$ plants were fertile and could produce $F_{2}$ seeds, $0.05 \mathrm{~g}$ of $F_{1}$ seeds from each reciprocal cross was used to infest soil in pots that were then planted with maize '8338-1'. As the $\mathrm{F}_{1}$ plants emerged and flowered, they were backcrossed reciprocally to randomly selected parental and $\mathrm{F}_{1}$ hybrid plants as pollen donors or recipients. Reproductive success was determined as previously described. Tests for germination and viability were conducted on 3-month-old seeds. The cumulative means of capsule formation, seed viability, and germination in each generation were computed and the viability and germination means separated using LSMEANS on SAS (SAS Institute, Cary, NC). Tests for pathogenicity on maize were conducted by infesting soil in pots with $0.05 \mathrm{~g}$ of parasite seeds from each cross and planting maize '8338-1' in each pot. Successful parasitism was determined, after 6 weeks of maize growth, by the presence of at least one live parasite that had attached to the maize roots and emerged from the soil.

Seed germination tests over time. These tests were conducted to determine the period(s) of dormancy in seeds of SA, SH, and their hybrids after pollination and seed set. Seeds from the intraspecific crosses (in Purdy notation) SA/SA and SH/SH and those from the interspecific $\mathrm{F}_{1}$ reciprocal crosses $\mathrm{SA}$ (female)/SH (male) and SH (female)/SA (male) were used. Parasite seeds were collected after capsule dehiscence and immediately surface-disinfested for $5 \mathrm{~min}$ in a $1 \%$ solution of sodium hypochlorite. The seeds were then thoroughly rinsed with distilled water, air-dried, and stored in glass vials at ambient temperature $\left(28^{\circ} \mathrm{C}\right)$ throughout the period of the study. Before each germination test, a fresh germination stimulant solution (10 mg of GR24 per liter) was prepared from a $100 \mathrm{mg}$ of GR24 stock solution per liter that was stored at $4^{\circ} \mathrm{C}$. At 2-week intervals, between 360 to 720 seeds from each cross were tested for germination. These tests began at 28 DAP (harvested 14 DAP and conditioned for an additional 14 days) and continued up to 546 DAP. The experiment was repeated three times, and the pooled data were analyzed using the General Linear Model procedure of SAS. Means of the seed germination tests in each cross were estimated using the MEANS procedure of SAS. Dormancy period was designated as the length of time from pollination until the first germination peak.

Chromosome counts. A new procedure for counting Striga spp. chromosomes was developed for this study. Because roots are poorly developed in SH and SA, shoot meristems of unemerged seedlings were used for mitotic chromosome counts. Seedlings of SH populations from Bida and Kano and SA from Kano and Jos, Nigeria, were examined. To obtain these seedlings with ease, seeds from each parasite were used to infest pots containing vermiculite in which maize '8338-1' was planted. A solution of Stern's MiracleGro (1 g per liter; Stern's Miracle-Gro Products, Inc., Port Washington, NY) containing $15 \% \mathrm{~N}, 30 \% \mathrm{P}_{2} \mathrm{O}_{5}$, and $15 \% \mathrm{~K}_{2} \mathrm{O}$ was used as a nutrient source and applied to each pot weekly at the rate of $50 \mathrm{ml}$ per pot. When the first parasites began to emerge, 30 to 35 days after planting, the maize roots were gently washed in running water to remove the vermiculite particles. All stages of unemerged parasite seedlings were collected in a beaker containing water. In the laboratory, the seedlings were placed on absor-

TABLE 1. Reproductive success, seed viability, and germination of Striga aspera (SA), S. hermonthica (SH), and their hybrids and backcrosses

\begin{tabular}{|c|c|c|c|c|c|c|}
\hline Generation & Crosses $^{\mathrm{a}}$ & Number of crosses & $\%$ Capsules formed & $\%$ Seed viability $^{\mathrm{b}}$ & $\%$ Seed germination $^{b}$ & Pathogenic on maize ' $8338-1$ ' \\
\hline Parental & SA/SA & 73 & 81 & 73 & 60 & $+^{\mathrm{c}}$ \\
\hline Parental & $\mathrm{SH} / \mathrm{SH}$ & 30 & 93 & 79 & 72 & + \\
\hline $\mathrm{F}_{1}$ hybrid & $\mathrm{SA} / \mathrm{SH}$ & 106 & 74 & 14 & 23 & + \\
\hline $\mathrm{F}_{1}$ hybrid & SH/SA & 94 & 93 & 37 & 31 & + \\
\hline $\mathrm{F}_{2}$ hybrid & $\mathrm{SA} / \mathrm{SH} / / \mathrm{SA} / \mathrm{SH}$ & 16 & 88 & 9 & 3 & + \\
\hline $\mathrm{F}_{2}$ hybrid & $\mathrm{SH} / \mathrm{SA} / / \mathrm{SA} / \mathrm{SH}$ & 13 & 87 & 13 & 15 & + \\
\hline $\mathrm{F}_{2}$ hybrid & $\mathrm{SA} / \mathrm{SH} / / \mathrm{SH} / \mathrm{SA}$ & 13 & 91 & 24 & 13 & + \\
\hline $\mathrm{F}_{2}$ hybrid & $\mathrm{SH} / \mathrm{SA} / / \mathrm{SH} / \mathrm{SA}$ & 28 & 77 & 22 & 10 & + \\
\hline Backcross & $\mathrm{SA} / \mathrm{SH} / / \mathrm{SA}$ & 22 & 90 & 26 & 16 & + \\
\hline Backcross & $\mathrm{SA} / \mathrm{SH} / / \mathrm{SH}$ & 17 & 86 & 10 & 14 & + \\
\hline Backcross & $\mathrm{SH} / \mathrm{SA} / / \mathrm{SA}$ & 11 & 95 & 18 & 13 & + \\
\hline Backcross & $\mathrm{SH} / \mathrm{SA} / / \mathrm{SH}$ & 17 & 79 & 15 & 19 & + \\
\hline Backcross & $\mathrm{SA} / / \mathrm{SA} / \mathrm{SH}$ & 41 & 73 & 14 & 12 & + \\
\hline Backcross & $\mathrm{SA} / / \mathrm{SH} / \mathrm{SA}$ & 27 & 68 & 21 & 6 & + \\
\hline Backcross & $\mathrm{SH} / / \mathrm{SA} / \mathrm{SH}$ & 27 & 84 & 17 & 20 & + \\
\hline Backcross & $\mathrm{SH} / / \mathrm{SH} / \mathrm{SA}$ & 27 & 74 & 13 & 5 & + \\
\hline
\end{tabular}

a All crosses in Purdy notation (“/" = initial cross(es): female parent/male parent) and (“//“" second cross: $\mathrm{F}_{1}$ or parent species [female]//parent species or $\mathrm{F}_{1}$ [male]).

b Determined at 90 days after pollination.

$\mathrm{c}+$ indicates pathogenicity and successful development of the parasite on maize roots. 
bent paper to remove excess water and then transferred into a $0.5 \%$ aqueous solution of colchicine at $28^{\circ} \mathrm{C}$ for $3 \mathrm{~h}$. Afterwards, the seedlings were fixed for at least $24 \mathrm{~h}$ in cold Carnoy's solution I containing a mixture of glacial acetic acid and absolute ethanol solutions $(1: 3 \mathrm{vol} / \mathrm{vol})$. The seedlings were then hydrolyzed in $1 \mathrm{~N}$ $\mathrm{HCl}$ at $60^{\circ} \mathrm{C}$ for $10 \mathrm{~min}$. After hydrolysis, the seedlings were rinsed in water and dried on absorbent paper. The top $2 \mathrm{~mm}$ of the shoot tip of each seedling was cut on a glass slide, stained in lacto-propionic-orcein stain solution for $2 \mathrm{~min}$, and squashed under a cover slip. To spread the cells adequately, the cover slip was tapped gently with the end of a pencil. Well-spread cells with distinct chromosomes were selected, counted, and photographed under oil im-
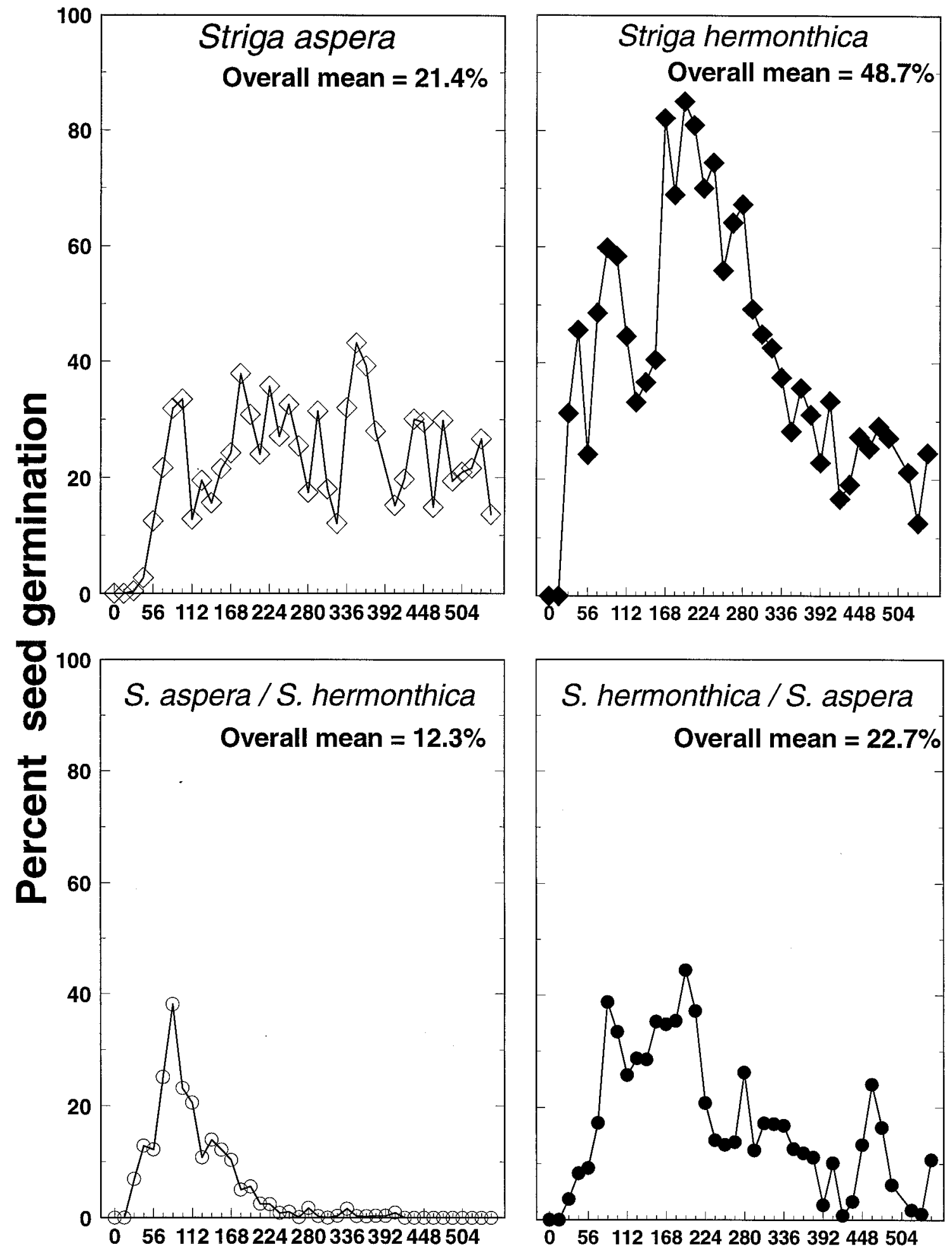

Days after pollination

Fig. 1. Germination patterns of seeds of Striga aspera, $S$. hermonthica, and their reciprocal $\mathrm{F}_{1}$ hybrids over time using a $10 \mathrm{mg}$ of GR24 solution per liter as a germination stimulant. 
mersion at $\times 1,000$ magnification using a compound microscope. More than 250 seedlings of each species were examined. The Univariate Procedure of SAS was used to generate the grand mean and mode of the chromosome counts for each species from which the chromosome numbers were estimated.

\section{RESULTS}

Hybridization. There was successful capsule formation and seed production in all the cross combinations attempted (Table 1). All the combinations of backcrosses using $F_{1}$ hybrid plants as pollen donors or recipients with the parents and $F_{1}$ hybrids resulted in successful seed set. Backcrosses having SA as the maternal parent produced lower capsule formation than other crosses. The lowest capsule set of $68 \%$ was recorded from the cross between SA (female) and the $\mathrm{F}_{1}$ hybrid SH/SA (male). However, the reciprocal of this cross, SH/SA (female)//SA (male), produced the highest capsule set of $95 \%$. Capsule formation of more than $90 \%$ was recorded for intraspecific $\mathrm{SH}$ crosses, the interspecific $\mathrm{F}_{1}$ hybrid (SH/SA), the $\mathrm{F}_{2}$ hybrid SA/SH//SH/SA, and the backcross SA/SH (female)//SA (male).

Hybrid plants ( $F_{1}$ plants) had physical features intermediate to the parent plants. Independent of the maternal parent, the length of the corolla tube above the calyx of the $\mathrm{F}_{1}$ plants was longer than that of SH and shorter than that of SA. When SA was the maternal parent, glandular hairs on the corolla tube were always present. The opposite occurred with SH as the maternal parent. Most of the $\mathrm{F}_{2}$ plants and backcrosses physically resembled SH more than SA.

Viability, germination, and pathogenicity test. Test results presented in Table 1 indicate that seeds obtained from all the crosses were viable, germinable, and could infect and grow successfully on maize ' $8338-1$ '. However seed viability and seed germinability of the interspecific hybrids and backcrosses were significantly $(P \leq$ $0.05)$ less than the intraspecific parental crosses. Seed viability was $77 \%$ for the parents, $26 \%$ for the $F_{1}$ seeds, and $17 \%$ for the $F_{2}$ and backcross seeds. Seed germinability was $66 \%$ for the parents, $27 \%$ for the $\mathrm{F}_{1}$ seeds, $10 \%$ for the $\mathrm{F}_{2}$ seeds, and $13 \%$ for the backcrosses. Except for a few cases, seed viability was greater than seed germinability, suggesting that not all the viable seeds germinated.

Seed germination tests over time. Results of the parasite seed germination tests conducted over time are shown in Figure 1. Freshly harvested $\mathrm{SH}$ seeds were the first to germinate with more than $30 \%$ germination at 28 DAP. The germination of SH seeds did not drop below 24\% 1 year after pollination. Initially, SA and $\mathrm{F}_{1}$ hybrid seeds germinated poorly, but germination increased with time, peaking at 84 to 98 DAP. The germination life span of seeds from the hybrid SA/SH was short, and seeds ceased to germinate at 238 DAP. The highest germination for these seeds was at 84 DAP. Other seeds showed multiple germination peaks and were still germinable 1 year after pollination. The germination peak between 84 to 98 DAP was common for all the crosses. In SA, SH, and the hybrid SH/SA, a second and third germination peak were evident between 169 to 196 DAP and between 280 to 336 DAP. Overall mean germination of SH seeds was more than double germination of the other seeds. However, mean germination of SH/SA was equivalent to the germination of SA seeds, while germination of SA/SH seeds was the least.
Chromosome counts. A summary of the range of chromosome counts observed is shown in Table 2. Chromosome counts were obtained from shoot-tip preparations from 17 SA and $36 \mathrm{SH}$ seedlings that had well-spread and visible chromosomes. Chromosome counts in nuclei from the same shoot tips varied depending on the level of spread and visibility of the chromosomes. From the mode of the chromosome counts, the chromosome number for SA was estimated as $n=18$, and for SH was $n=19$. The means of the chromosome counts were not used to estimate chromosome number, because observed counts could rarely be greater than the exact number of chromosomes. The count distributions were, therefore, not normal and means were not the best estimates of a central tendency.

\section{DISCUSSION}

This study provides the first detailed report on the hybridization potential and reproductive success in $\mathrm{SA}, \mathrm{SH}$, and their hybrids. The $\mathrm{F}_{1}, \mathrm{~F}_{2}$, and backcross seeds from crosses between the two species were viable and germinable with the capacity to infect a maize host.

A new workable system was developed, using shoot-tip squashes, for counting chromosomes in root parasites that have primary haustoria in which root tips are not easily available. The chromosome counts, based on the mode of each species, of $n=18$ for SA and $n=19$ for SH were estimated from mitotic chromosome counts and indicate that these two species are likely to be diploids. These counts are contrary to earlier estimates of $n=27$ for SA and $n=32$ for $\mathrm{SH}$ (7) and $n=30$ for SA and $n=40$ for SH (4). However, as Parker and Riches (11) suggested, the previously reported disparity in chromosome number between the species would not likely lead to the degree of successful hybridization found in this study. The differences in chromosome counts may have been due to methodology and the materials used. Chromosome counts in the study by Musselman et al. (7) were done on pollen mother cells after long, and sometimes inadequate, storage that may have led to chromosome breakdown (L. J. Musselman, personal communication). The range in chromosome counts observed in the current study was probably largely due to broken and overlapping chromosomes. In the Iwo et al. (4) study, counts were done on squashed anthers and the observed nuclei may have been from anther wall cells, rather than pollen cells, or a mix of both. If this were the case, diploid chromosome counts could have been mistakenly interpreted as haploid, and the actual haploid estimates would be closer to $n=15$ for SA and $n=20$ for SH, thus approaching the estimates obtained in this study. No measures of central tendency or variability in chromosome counts were reported by either Iwo et al. (4) or Musselman et al. (7).

The apparent difference of only one meiotic chromosome between the species may account for the high degree of hybridization success and relatively large number of fertile progeny. This implies that natural hybridizations can occur, since both species are sympatric in West Africa and are strictly allogamous with common pollinators. No effective barriers restricting the species' ability to cross were observed, thus both species may serve as gene reservoirs for each other and their genetic pool may be larger than earlier envisaged. The lack of previous reports on natural hybridization may be due to the close resemblance of the $F_{1}$ hybrids to both parent species (and also the close resemblance between the species). In nature,

TABLE 2. Summary of mitotic chromosome counts in Striga aspera and Striga hermonthica

\begin{tabular}{|c|c|c|c|c|c|c|}
\hline Species & $\begin{array}{l}\text { No. of seedlings examined/ } \\
\text { No. with countable chromosomes }\end{array}$ & No. of nuclei counted & $\begin{array}{l}\text { Range of mitotic } \\
\text { chromosome counts }^{\mathrm{a}}\end{array}$ & $\begin{array}{c}\text { Mean of mitotic } \\
\text { chromosome number }^{b}\end{array}$ & Standard deviation & $\begin{array}{c}\text { Mode of mitotic } \\
\text { chromosome number }^{\mathrm{c}}\end{array}$ \\
\hline S. aspera & $256 / 17$ & 63 & $31-38$ & 34.8 & 1.95 & 36 \\
\hline S. hermonthica & $350 / 36$ & 95 & $26-39$ & 34.3 & 3.36 & 38 \\
\hline
\end{tabular}

a Range determined from minimum and maximum chromosome counts per nuclei.

${ }^{\mathrm{b}}$ Overall mean chromosome number from means of chromosome numbers per seedling.

c Overall mode (most frequently occurring value) of chromosome number from mode of chromosome numbers per seedling. 
the hybrids could be easily mistaken as either of the two parent species and go unnoticed. Thus, hybrids may occur frequently in nature, but remain undetected from the species present in greatest abundance.

The use of $F_{1}$ hybrids as maternal parents in backcrosses with parental species produced a high percent of filled seed capsules, while in the reciprocal of these crosses there were fewer capsules, resulting in poorer seed production. However, the significantly lower viability and germinability of the hybrid and backcrossed seeds compared with parental seeds suggests less than $100 \%$ compatibility between SA and $\mathrm{SH}$. These differences, in combination with the chromosome difference, support continued taxonomic separation of the species. However, the ability of both species to interbreed successfully suggests that their separation at the species level may be too great and that they may be more closely related, perhaps at a subspecies level.

Doggett (3) suggested that seed dormancy was an adaptation in Striga species responsible for preventing seeds from germinating during unfavorable environmental conditions that frequently occur at the end of the growing season. Our findings showed that, for both species and the $F_{1}$ hybrids, dormancy period, as defined by the length of time after pollination until the first germination peak, was less than 84 days. In $\mathrm{SH}, 31 \%$ germination was recorded as early as $28 \mathrm{DAP}$ and the first germination peak occurred at 56 DAP. This implies that for this species seed dormancy period is either very short or nonexistent. The finding that $\mathrm{SH}$ seeds collected from $\mathrm{Abu}$ Naama in Sudan gave a high of $80 \%$ germination in the first 3 months after harvest $(8,9)$ may be the rule rather than the exception.

Apart from the hybrid SA/SH, which had relatively short seed longevity, seeds of the other crosses continued to germinate after 1 year in storage. The germination patterns were characterized by peaks of high germination at frequent intervals. This rise and fall in the germination of SH seeds with time was also observed by Vallance (16), who found that germination does not take place until respiration in the $\mathrm{SH}$ seeds falls below a critical value. The fluctuating patterns of parasite seed germination over time suggest that to ascertain the true germination of these parasite seeds there is the need to conduct tests over time in all germination-related studies. In this study, parasite seeds from the same source occasionally gave higher germination than the estimate of viability determined from the tetrazolium test. This supports the findings by Bradbeer (2) that the presence of certain adverse factors in some seeds makes the tetrazolium test less sensitive and should, therefore, not be used as an absolute test for seed viability.

\section{ACKNOWLEDGMENTS}

Research supported, in part, by USAID grant DHR-5600-G-00-1021-00 provided to the Old Dominion University Research Foundation. Approved as International Institute of Tropical Agriculture manuscript IITA/97/JA/27.

\section{LITERATURE CITED}

1. Bebawi, F. F., Eplee, R. E., and Norris, R. S. 1984. Effect of age, size, and weight of witchweed seeds on host/parasite relations. Phytopathology 74:1074-1078.

2. Bradbeer, J. W. 1994. Seed Dormancy and Germination-Tertiary Level Biology Series. Blackie Academic and Professional Press, London.

3. Doggett, H. 1984. Striga-Its biology and control-An overview. Pages 27-36 in: Proc. Workshop Striga Biol. Control. E. S. Ayensu, H. Doggett, R. D. Keynes, J. Marton-Lefvre, L. J. Musselman, C. Parker, and A. Pickering, eds. International Council of Scientific Union Press, Paris.

4. Iwo, G. A., Husaini, S. W. H., and Olaniyan, G. O. 1993. Cytological observations and distribution of Striga species in central part of Nigeria. Feddes Repert. 104:7-8, 497-501.

5. Johnson, A. W., Roseberry, G., and Parker, C. 1976. A novel approach to Striga and Orobanche control using synthetic germination stimulants. Weed Res. 16:223-227.

6. Musselman, L. J. 1980. The biology of Striga, Orobanche, and other root parasitic weeds. Annu. Rev. Phytopathol. 18:463-489.

7. Musselman, L. J., Bharathalaksmi, Safa, S. B., Knepper, D. A., Mohamed, K. I., and White, C. L. 1991. Recent research on the biology of Striga asiatica, S. gesnerioides and S. hermonthica. Pages 31-41 in: Combating Striga in Africa. Proc. Int. Workshop Organ. IITA, ICRISAT IDRC. S. K. Kim, ed. International Institute of Tropical Agriculture, Ibadan, Nigeria.

8. Parker, C. 1983. Factors influencing Striga seed germination and host parasite specificity. Pages 31-35 in: Proc. Int. Workshop Striga, IDRC/ ICRISAT, 2nd. International Crops Research Institute for the Semi-Arid Tropics, Patancheru, India.

9. Parker, C. 1984. The physiology of Striga spp.: Present state of knowledge and priorities for future research. Pages 179-194 in: Proc. Workshop Striga Biol. Control. E. S. Ayensu, H. Doggett, R. D. Keynes, J. Marton-Lefvre, L. J. Musselman, C. Parker, and A. Pickering, eds. International Council of Scientific Union Press, Paris.

10. Parker, C. 1991. Flower morphology in Striga hermonthica and Striga aspera. Haustorium (Parasitic Plant Newsl., Old Dominion Univ., Norfolk, VA) 26:4-5.

11. Parker, C., and Riches, C. R. 1993. Parasitic Weeds of the World: Biology and Control. CAB International, Wallingford, United Kingdom.

12. Pieterse, A. H., and Pesch, C. J. 1983. The witchweeds (Striga spp.)-A review. Abstr. Trop. Agric. 9:9-37.

13. Ramaiah, K. V., Parker, C., Vasudeva Rao, M. J., and Musselman, L. J. 1983. Striga Identification and Control Handbook. Information Bull. 15. International Crops Research Institute for the Semi-Arid Tropics. Patancheru, India.

14. Raynal-Roques, A. 1991. Diversification in the genus Striga. Pages 251261 in: Int. Symp. Parasitic Weeds, 5th. J. K. Ransom, L. J. Musselman, A. D. Worsham, and C. Parker, eds. CIMMYT (International Maize and Wheat Improvement Center), Nairobi, Kenya.

15. Safa, S. B., Jones, B. M. G., and Musselman, L. J. 1984. Mechanisms favouring out-breeding in Striga hermonthica (Scrophulariaceae). New Phytol. 96:299-305.

16. Vallance, K. B. 1951. Studies on the germination of seeds of Striga hermonthica. III. On the nature of pretreatment and after ripening. Ann. Bot. 15:109-128. 